\title{
Correction to: Management of Neurofibromatosis Type 2 Associated Vestibular Schwannomas
}

\author{
Huan Jia ${ }^{1,2,3} \cdot$ Ghizlene Lahlou $^{1,2} \cdot$ Hao $\mathrm{Wu}^{3}$ - Olivier Sterkers ${ }^{1,2} \cdot$ Michel Kalamarides $^{1,4,5}$
}

Published online: 14 April 2021

(C) Springer Science+Business Media, LLC, part of Springer Nature 2021

\section{Correction to: Current Otorhinolaryngology Reports https://doi.org/10.1007/s40136-021-00341-x}

The original version of this article unfortunately contained a mistake. The second author name is misspelled, that "Ghizlene Lalhou" should be "Ghizlene Lahlou". The original article has been corrected.

Publisher's Note Springer Nature remains neutral with regard to jurisdictional claims in published maps and institutional affiliations.

The online version of the original article can be found at https://doi.org/ 10.1007/s40136-021-00341-x

Michel Kalamarides

michel.kalamarides@aphp.fr

Huan Jia

huan.jia.orl@shsmu.edu.cn

Ghizlene Lahlou

ghizlene_lahlou@yahoo.fr

Hao Wu

wuhao@shsmu.edu.cn

Olivier Sterkers

o.sterkers@icloud.com
Sorbonne Université, Paris, France

2 AP-HP, GHU Pitié-Salpêtrière, Service ORL, Otologie, implants auditifs et chirurgie de la base du crâne, Paris, France

3 Department of Otolaryngology Head \& Neck Surgery, Shanghai Ninth People's Hospital, Affiliated to Shanghai Jiaotong University School of Medicine, Shanghai, China

4 AP-HP, GHU Pitié-Salpêtrière, Service Neurochirurgie, Paris, France

5 Service de neurochirurgie, Hôpital Pitié-Salpêtrière, 47-83 boulevard de l'Hôpital, 75013 Paris, France 